ACCEPTED MANUSCRIPT

\title{
High speed chalcogenide glass electrochemical metallization cells with various active metals
}

To cite this article before publication: Mark Anthony Hughes et al 2018 Nanotechnology in press https://doi.org/10.1088/1361-6528/aac483

\section{Manuscript version: Accepted Manuscript}

Accepted Manuscript is "the version of the article accepted for publication including all changes made as a result of the peer review process, and which may also include the addition to the article by IOP Publishing of a header, an article ID, a cover sheet and/or an 'Accepted Manuscript' watermark, but excluding any other editing, typesetting or other changes made by IOP Publishing and/or its licensors"

This Accepted Manuscript is @ 2018 IOP Publishing Ltd.

During the embargo period (the 12 month period from the publication of the Version of Record of this article), the Accepted Manuscript is fully protected by copyright and cannot be reused or reposted elsewhere.

As the Version of Record of this article is going to be / has been published on a subscription basis, this Accepted Manuscript is available for reuse under a CC BY-NC-ND 3.0 licence after the 12 month embargo period.

After the embargo period, everyone is permitted to use copy and redistribute this article for non-commercial purposes only, provided that they adhere to all the terms of the licence https://creativecommons.org/licences/by-nc-nd/3.0

Although reasonable endeavours have been taken to obtain all necessary permissions from third parties to include their copyrighted content within this article, their full citation and copyright line may not be present in this Accepted Manuscript version. Before using any content from this article, please refer to the Version of Record on IOPscience once published for full citation and copyright details, as permissions will likely be required. All third party content is fully copyright protected, unless specifically stated otherwise in the figure caption in the Version of Record.

View the article online for updates and enhancements. 


\title{
High speed chalcogenide glass electrochemical metallization cells with various active metals
}

\author{
Mark A. Hughes ${ }^{1, a}$, Alexander Burgess ${ }^{1}$, Steven Hinder ${ }^{2}$, A. Baset Gholizadeh ${ }^{3}$, Christopher Craig $^{4}$, \\ Daniel W. Hewak ${ }^{4}$ \\ ${ }^{1}$ Joule Physics Laboratory, School of Computing, Science \& Engineering, University of Salford, Salford M5 4WT, United \\ Kingdom \\ ${ }^{2}$ The Surface Analysis Laboratory, Department of Mechanical Engineering Sciences, University of Surrey, Guildford, GU2 \\ 7XH, United Kingdom \\ ${ }^{3}$ Photon Science Institute, University of Manchester, Manchester, M13 9PL, United Kingdom \\ ${ }^{4}$ Optoelectronics Research Centre, University of Southampton, Southampton SO17 1BJ, United Kingdom
}

We fabricated electrochemical metallization (ECM) cells using a GaLaSO solid electrolyte, a InSnO inactive electrode and active electrodes consisting of various mețals ( $\mathrm{Cu}, \mathrm{Ag}, \mathrm{Fe}, \mathrm{Cu}, \mathrm{Mo}, \mathrm{Al}$ ). Devices with $\mathrm{Ag}$ and $\mathrm{Cu}$ active metals showed consistent and repeatable resistive switching behaviour, and had a retention of 3 and $>43$ days, respectively; both had switching speeds of $<5$ ns. Devices with $\mathrm{Cr}$ and Fe active metals displayed incomplete or intermittent resistive switching, and devices with Mo and $\mathrm{Al}$ active electrodes displayed no resistive switching ability. Deeper penetration of the active metal into the GaLaSO layer resulted in greater resistive switching ability of the cell. The off-state resistivity was greater for more reactive active metals which may be due to a thicker intermediate layer. 


\section{Introduction}

Chalcogenide glasses possess a range of unique and technologically beneficial material properties such as high nonlinear refractive indices, making them suitable for all-optical telecoms signal processing [1]. They display persistent p-type conductivity, which can now be reversed by ion implantation for exploitation in optoelectronic devices [2]. They can switch readily between a glassy and crystalline state when heated optically or electrically. This has been exploited for commercially available phase change memory, which has speed and endurance advantages over flash memory. In addition, various metal ions can diffuse with relative ease through solid chalcogenides glasses. The diffusion process, particularly of Ag, can be significantly enhanced by illumination [3], with applications in photolithography and waveguide formation. The diffusion can also be enhanced by an electric field, with applications in phase change memory where electric field induced Ag doping of $\mathrm{Sb}_{2} \mathrm{~S}_{3}$ reduces its crystallisation time [4], in battery technology [5], and ECM cells. In ECM cells, metal ions diffuse from an active metal (M) electrode under the influence of a positive electric field into a solid electrolyte, the metal ions then precipitate into a metallic filament which forms a conductive bridge between an inactive electrode and the active electrode, drastically reducing the resistance of the cell. A negative electric field can then be used to electrochemically dissolve the filament, switching the cell back to a high resistance state. This reversible resistive switching can be used as the basis for a memory device. Chalcogenide ECM cells could offer similar benefits of phase change memory, but without the trade-off between crystallisation speed and retention time [6], and potentially lower power consumption, faster switching speed, higher density and greater endurance [7-10]. Furthermore, chalcogenide ECM devices could form the synapses in solid-state neuromorphic circuits [11].

Although 2-Mbit chalcogenide ECM memory arrays [12] and a $10 \times 10 \mathrm{~nm} \mathrm{HfO}$, based ECM cell have been demonstrated [13], the development of ECM technology is far behind that of phase change memory. The chalcogenide glasses commonly used for ECM cells are the Ge based family of glasses also commonly used in phase change memory, and include GeSbTe [14, 15], $\mathrm{As}_{2} \mathrm{~S}_{3}$ [16], GeSe $[15,17,18]$, GeTe [19], AgGeSe [20] and AgGeS [21]. GaLaSO has a higher crystallisation temperature than most chalcogenides, which is particularly important when considering its back-end-of-line (BEOL) compatibility ie the fabrication interconnects above memory elements in a memory array [22]. Depending on the process used, the chalcogenide should be able to withstand temperatures of $400{ }^{\circ} \mathrm{C}$ for a standard $\mathrm{Cu} /$ dielectric combination [23], or $800{ }^{\circ} \mathrm{C}$ for high temperature annealed oxides [24]. The glass transition temperature $\left(T_{g}\right)$ and crystallization temperature $\left(T_{p}\right)$ are given in Table 1 for the chalcogenide solid electrolytes used in ECM cells. This shows GaLaSO has the highest $\mathrm{T}_{\mathrm{g}}$ and $\mathrm{T}_{p}$, and the most comprehensive BEOL process compatibility.

GaLaSO has a high resistivity; we have previously measured the temperature dependence of resistivity of an undoped GaLaSO sputtered film between temperatures of $280^{\circ} \mathrm{C}$ and $180^{\circ} \mathrm{C}$, where the resistivity was $10^{12} \Omega \mathrm{cm}$ at $180^{\circ} \mathrm{C}$ [2]. Below $180^{\circ} \mathrm{C}$ the resistivity was too high to measure, however, projecting the Arrhenius plot to room temperature gave a resistivity of $\sim 10^{19} \Omega \mathrm{cm}$. The subsequent potential for a high off-state resistance makes GaLaSO based ECM devices suitable for applications where battery life is critical [25]. Modelling indicates that the size and shape of the filament depend on the Young's modulus of the solid electrolyte, with high and low values leading to wire and dendritic shapes, respectively. The Young's modulus of GaLaSO is $59 \mathrm{GPa}$, compared to 11 GPa for GeSe [26], indicating that GaLaSO based ECM cells will have narrower wire-like filaments, and therefore more suitable for high density memory arrays than Ge-chalcogenide based ECM cells. Despite the large and growing body of research into chalcogenide ECM cells, a rigorous investigation of the performance of ECM cells fabricated with the same chalcogenide and a variety of active metals is lacking in the literature. In this work, we characterise GaLaSO based ECM cells with various active metals ( $\mathrm{Ag}, \mathrm{Al}, \mathrm{Cr}, \mathrm{Cu}, \mathrm{Fe}$ and $\mathrm{Mo}$ ). 
Table 1. Thermal properties of chalcogenide solid electrolytes used in ECM cells

\begin{tabular}{llll}
\hline Chalcogenide & $\mathrm{T}_{\mathrm{g}}\left({ }^{\circ} \mathrm{C}\right)$ & $\mathrm{T}_{\mathrm{p}}\left({ }^{\circ} \mathrm{C}\right)$ & ref \\
\hline $\mathrm{Ge}_{2} \mathrm{Sb}_{2} \mathrm{Te}_{5}$ & 100 & 140 & {$[27]$} \\
$\mathrm{Ge}_{20} \mathrm{Te}_{80}$ & 159 & 220 & {$[28]$} \\
$\mathrm{As}_{2} \mathrm{~S}_{3}$ & 200 & & {$[29]$} \\
$\mathrm{GeSe}$ & 324 & 340 & {$[28]$} \\
$\mathrm{GeS}$ & 456 & 650 & {$[30]$} \\
$\mathrm{GaLaS}$ & 559 & 715 & {$[31]$} \\
GaLaSO & 567 & 821 & {$[31]$} \\
\hline \hline
\end{tabular}

\section{Experimental}

We prepared a sputtering target for the GaLaSO film by batching $77.5 \%$ gallium sulphide $\left(\mathrm{Ga}_{x} \mathrm{~S}_{y}\right)$ and $22.5 \%$ lanthanum oxide $\left(\mathrm{La}_{2} \mathrm{O}_{3}\right)(\mathrm{mol} \%)$ in a dry-nitrogen purged glovebox and homogenized with the aid of a roller mixer for 1 hour. The mixture was melted at $1150^{\circ} \mathrm{C}$ for 24 hours in a vitreous carbon crucible, placed inside an argon-purged silica tube. The glass was then annealed at $490^{\circ} \mathrm{C}$ for 24 hours. GaLaSO can be readily sputtered into amorphous films with a high compositional uniformity and fewer of the local defects present in bulk glass [32]. We use the same tool and similar parameters that we have used previously for sputtering other chalcogenides such as GeSbTe, GeSe, GeTe and GeS. We fabricated the ECM devices by sputtering $100 \mathrm{~nm}$ of GaLaSO onto $100 \mathrm{~nm}$ InSnO (ITO)-coated borosilicate glass substrates with a Kurt J. Lesker NANO38- SPUTTER thin film deposition system with a background pressure of 3 mTorr, a deposition power of $60 \mathrm{~W}$ and an argon gas flow of $15 \mathrm{ccpm}$. To fabricate the active metal top contacts we evaporated $\mathrm{Cu}$ and $\mathrm{Al}$ or sputtered $\mathrm{Mo}, \mathrm{Fe}, \mathrm{Cr}$ and $\mathrm{Ag}$, all with a thickness of $\sim 100 \mathrm{~nm}$, through a shadow mask with $500 \mu \mathrm{m}$ square holes. We chose ITO for the inactive electrode because of its expected low diffusability in chalcogenides. The device structure is illustrated in Figure 1(a). Time-of-flight secondary ion mass spectrometry (ToF-SIMS) depth profiles were acquired on an ION-TOF GmbH (Munster, Germany) TOF.SIMS 5 instrument using a $25 \mathrm{keV} \mathrm{Bi}_{3}{ }^{+}$analysis ion beam, and a $3 \mathrm{keV} \mathrm{Cs}$ ion sputter tool.

\section{Results and discussion}

Figure 1 (b) and (c) show typical IV measurements of the Ag and Cu contact devices, respectively. Both devices show set-reset behaviour, with the Ag contact device setting at $\sim 1.4 \mathrm{~V}$ and resetting at $\sim-4.6 \mathrm{~V}$, and the Cu contact setting at $\sim 0.6 \mathrm{~V}$ and resetting at $\sim-3.4 \mathrm{~V}$. Off-state and on-state resistances were $\sim 10 \mathrm{k} \Omega$ and $\sim 70 \Omega$, respectively, for both $\mathrm{Ag}$ and Cu devices. The IV sweep of a typical Fe contact device is shown in Figure 1 (d), these devices showed some set behaviour in the first one or two IV sweeps, setting at $\sim 1.1 \mathrm{~V}$. The low resistance on-state would break down as the voltage was swept higher, possibly due to break down of the filaments. $\mathrm{Cr}$ contact devices, shown in Figure 1 (e), showed intermittent switching behaviour with a possible set at $\sim 2 \mathrm{~V}$. The devices usually showed Ohmic behaviour with a resistivity of $6 \times 10^{10} \Omega \mathrm{cm}$. 
a

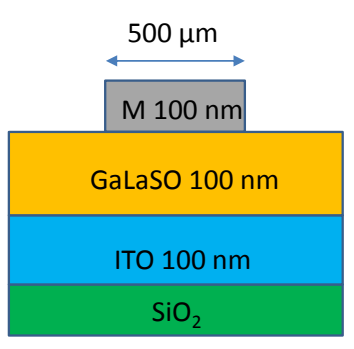

b

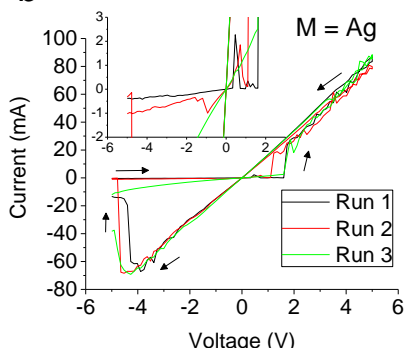

C

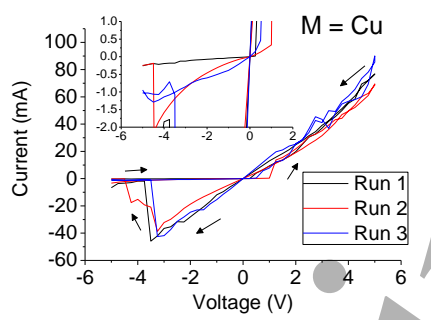

d

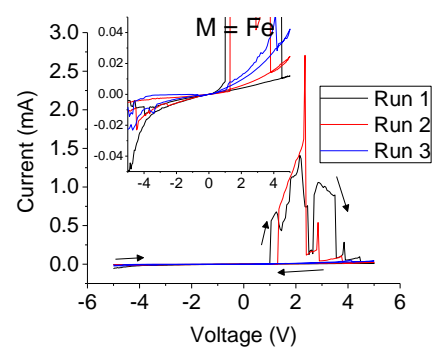

e

Figure. 1 (a) Schematic of the device structure, where ITO was used as the inactive electrode, and $\mathrm{M}$ is the active metal = $\mathrm{Ag}, \mathrm{Al}, \mathrm{Cr}, \mathrm{Cu}$, Fe or Mo. Three consecutive IV sweeps (Run 1 to 3 ) of the switching devices where the active metal is (b) $\mathrm{Ag}$, (c) $\mathrm{Cu},(\mathrm{d}) \mathrm{Fe},(\mathrm{e}) \mathrm{Cr}$.

Evaporated Al and sputtered Mo contact devices displayed persistent Ohmic behaviour with IV sweeps between -20 and $20 \mathrm{~V}$ and resistivities of $6 \times 10^{10} \Omega \mathrm{cm}$. The results for evaporated Al are in contrast to our previous results for sputtered Al contacts on GaLaSO [33] where we found resistive switching with a very high resistance ratio of $6 \times 10^{4}$. We postulated that the metal/chalcogenide interface had a significant effect on the restive switching mechanism because of significant changes in resistance ratio, and set and reset voltages after $\mathrm{Pb}$ ion implantation into the GaLaSO before $\mathrm{Al}$ deposition. Compared to evaporation, the sputtering process results in 1-2 orders of magnitude higher energy atoms with non-ballistic trajectories, resulting in denser films with smaller grain boundaries and better adhesion [34]. This could result in greater penetration of Al into the surface of GaLaSO when it is sputtered, which could explain why we only observe resistive switching from Al when it is sputtered. These parameters are detailed in Table 2. The resistance ratio of $\sim 100$ for the $\mathrm{Cu}$ and $\mathrm{Ag}$ devices compares to other chalcogenide ECM cells such as $2.5 \times 10^{3}$ for $\mathrm{Ge}_{2} \mathrm{Sb}_{2} \mathrm{Te}_{5}$ [14] and $1.9 \times 10^{4}$ for $\mathrm{Ag}_{20} \mathrm{Ge}_{20} \mathrm{~S}_{60}$ [21]. The relatively low resistance ratio is due to a relatively low off-state resistance which is caused by the high levels of doping by $\mathrm{Cu}$ and $\mathrm{Ag}$, as evidenced by the reduction in resistivity compared to undoped GaLaSO by at $\sim 13$ orders of magnitude. The off-state resistance should also scale linearly with device area, and assuming a single filament, the on-state resistance should not depend on device area. 
Table 2. Summary of the performance parameters for the various active electrodes used in our GaLaSO ECM cells. $¥$ Evaporated, tsputtered, $*$ after ref. [33].

\begin{tabular}{|c|c|c|c|c|c|c|c|}
\hline $\begin{array}{l}\text { Active } \\
\text { electrode }\end{array}$ & $\begin{array}{l}\text { Set } \\
\text { voltage } \\
\text { (V) }\end{array}$ & $\begin{array}{l}\text { Reset } \\
\text { voltage } \\
\text { (V) }\end{array}$ & $\begin{array}{l}\text { On-state } \\
\text { resistivity } \\
(\Omega \mathrm{cm})\end{array}$ & $\begin{array}{l}\text { Off-state } \\
\text { resistivity } \\
(\Omega \mathrm{cm})\end{array}$ & $\begin{array}{l}\text { Resistance } \\
\text { ratio }\end{array}$ & $\begin{array}{l}\text { Retention } \\
\text { (days) }\end{array}$ & $\begin{array}{l}\text { Switch } \\
\text { speed } \\
\text { (ns) }\end{array}$ \\
\hline Cuf & $0.6 \pm 0.3$ & $-3.4 \pm 0.1$ & $\begin{array}{l}1.8 \times 10^{4} \\
\pm 1.7 \times 10^{3}\end{array}$ & $\begin{array}{l}2.2 \times 10^{6} \\
\pm 1.3 \times 10^{6}\end{array}$ & 120 & 3 & \\
\hline $\mathrm{Ag}^{\dagger}$ & $1.4 \pm 0.2$ & $-4.6 \pm 0.3$ & $\begin{array}{l}1.5 \times 10^{4} \\
\pm 500\end{array}$ & $\begin{array}{l}1.6 \times 10^{6} \\
\pm 1.2 \times 10^{6}\end{array}$ & 103 & $>43$ & \\
\hline $\mathrm{Fe}^{\dagger}$ & $1.1 \pm 0.2$ & - & $\begin{array}{l}2.8 \times 10^{5} \\
\pm 4 \times 10^{4}\end{array}$ & $\begin{array}{l}1.6 \times 10^{8} \\
\pm 7 \times 10^{7}\end{array}$ & 570 & - & \\
\hline $\mathrm{Cr}^{+}$ & $2 \pm 0.2$ & - & $\begin{array}{l}1 \times 10^{7} \\
\pm 6 \times 10^{6}\end{array}$ & $\begin{array}{l}6 \times 10^{10} \\
\pm 2 \times 10^{10}\end{array}$ & 6000 & & \\
\hline Alt* & $2.4 \pm 0.4$ & $0.35 \pm 0.1$ & $\begin{array}{l}6 \times 10^{9} \\
\pm 1 \times 10^{9}\end{array}$ & $\begin{array}{l}3.6 \times 10^{14} \\
\pm 2 \times 10^{14}\end{array}$ & $6 \times 10^{4}$ & & - \\
\hline
\end{tabular}

The set and reset phenomena in chalcogenide ECM cells involve the respective electrochemical deposition and dissolution of conductive metal filaments [20]. In our GaLaSO ECM cells the application of a positive bias to $\mathrm{M}$ will cause further dissolution of $\mathrm{M}$ into the GaLaSO, described by the reaction $\mathrm{M} \rightarrow \mathrm{M}^{2+}+\mathrm{ze}^{-}$. The $\mathrm{M}^{2+}$ ions are then transported across the GaLaSO film by the positive electric field, and deposited at the ITO cathode, described by the reaction $\mathrm{M}^{2+}+\mathrm{ze}^{-} \rightarrow \mathrm{M}$; when a conductive $M$ filament bridges the electrodes, the device is set. The device should reset due to dissolution of the conductive filaments under the influence of a negative electric field, according to the reaction: $\mathrm{M} \rightarrow \mathrm{M}^{2+}+\mathrm{ze}$. The main classes of solid electrolytes used in ECM cells are chalcogenides and oxides. Chalcogenides have excellent ionic conductivity, but they often result in poor retention [35]. The moisture content of the solid electrolyte is important since a counter reaction to $\mathrm{M} \rightarrow \mathrm{M}^{2+}+\mathrm{ze}$ is required at the inactive electrode to maintain charge neutrality, and would typically be $1 / 2 \mathrm{O}_{2}+\mathrm{H}_{2} \mathrm{O}+2 \mathrm{e}^{-} \rightarrow 2 \mathrm{OH}^{-}$[36]. The standard reduction potential of $\mathrm{M}$ is relevant since it dictates the propensity for the active electrode to oxidise into mobile cations, and for metal filaments to precipitate and dissolve $[33,35]$. The polarizability of the $\mathrm{M}^{+} / \mathrm{M}$ redox reaction is also important since it dictates the required overvoltage [37]. The $\mathrm{Ag}^{+} / \mathrm{Ag}$ reaction typically has the lowest polarizability of active metals used in ECM devices. The inactive electrode can influence charge transfer in the solid electrolyte since in order to maintain charge neutrality, water must be reduced. Hence the electrocatalytic ability of the inactive electrode to reduce water will influence the concentration of $\mathrm{M}^{+}$in the solid electrolyte [38]. The electrocatalytic ability of $\operatorname{In}_{2} \mathrm{O}_{3}$ and $\mathrm{SnO}_{2}$ has been shown to be very low [39], which indicates that our ITO inactive electrode could be limiting device performance. 
a

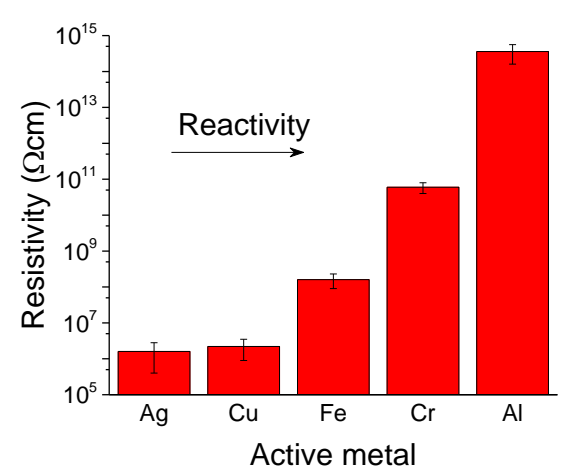

b
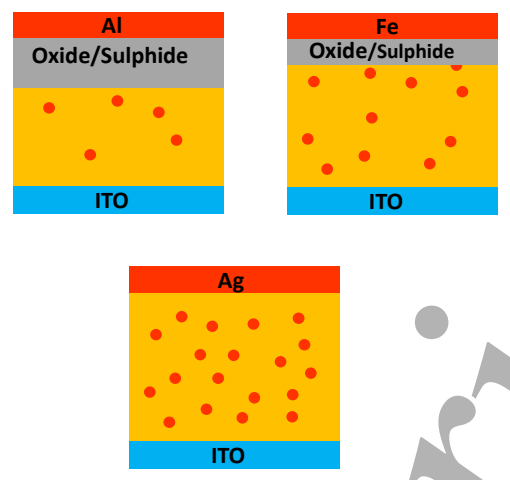

Figure. 2 (a) Off-state resistivity for the active metal used in our GaLaSO based ECM cells arranged in order of the reactivity series; Al data from ref.[33] (b) Illustration of our model for the device configuration in the off-state with $\mathrm{Al}, \mathrm{Fe}$ and $\mathrm{Ag}$ active electrodes.

Of particular note for our ECM devices is the large variation in off-state resistivity for the various active metals, ranging from $\sim 10^{6} \Omega \mathrm{cm}$ for $\mathrm{Ag}$ to $\sim 10^{14} \Omega \mathrm{cm}$ for Al. As an amorphous semiconductor, the resistivity of GaLaSO can be massively reduced by doping with metal ions [2]. Therefore, the off-state resistivity will be largely dictated by the concentration of diffused metal ions in the GaLaSO film which would dope, or alloy with, the GaLaSO and lower its resistivity. We found that the off-state resistivity of freshly deposited GaLaSO ECM devices was largely unchanged after serval sweep cycles, for all active electrodes. This indicates that the doping of the GaLaSO by the active electrode occurs without the application of a bias to the devices. The formation of an intermediate $\mathrm{MO}_{\mathrm{x}}$ layer between the active metal and solid electrolyte is a well know phenomenon in ECM devices [40-46]. The formation of an intermediate $\mathrm{MO}_{\mathrm{x}}$ layer is especially common when a reactive metal such as $\mathrm{Al}$ is used[43,44,46], forming $\mathrm{AlO}_{\mathrm{x}}$ layers of $\sim 5 \mathrm{~nm}$ for both Co doped gelatine[43] and $\mathrm{CuO}_{\mathrm{x}}[44]$ solid electrolytes. In valence change memory (VCM) devices with $\mathrm{TiO}_{2}$ solid electrolytes, a $3 \mathrm{~nm}$ thick Al-Ti-O layer formed at the interface of the Al electrode and $\mathrm{TiO}_{2}[46]$. The VCM switching mechanism is not thought to occur in the GaLaSO system [33]. The formation of intermediate oxide layers could therefore explain the large dependence of off-state resistivity on the active metal. The off-state resistivity of the our ECM devices with various active metals, arranged in order of the reactivity series is shown in Figure 2 (a). There is a clear trend of increasing off-state resistivity with increasing reactivity of the active metal. We therefore propose that in our GaLaSO ECM devices the more reactive active metals, such as $\mathrm{Al}$, will tend to form an intermediate $\mathrm{MO}_{x}$ layer which will itself increase the resistance of the cell and act as a barrier for $\mathrm{M}^{2+}$ ions to diffuse into the GaLaSO layer, which prevents doping and further increases the resistance of the cell. Because of the $\mathrm{S}$ content of GaLaSO we cannot rule out the formation of a $\mathrm{MS}_{\mathbf{x}}$ intermediate layer. Less reactive active metals, such as $\mathrm{Ag}$, will not tend to form an intermediate $\mathrm{MO}_{\mathrm{x}}$ layer, and the lack of a barrier will enable greater $\mathrm{M}^{2+}$ ion diffusion. This model is illustrated in Figure 2 (b). An analogous argument was made for VCM devices with various metal electrodes, in which metals with a higher oxygen affinity had higher on/off ratio and off-state resistance because of thicker interface layers, which block the diffusion of $\mathrm{O}^{2-}$ ions into the electrode [46].

Intermediate $\mathrm{MO}_{\mathrm{x}}$ layers have been found to improve the endurance[41, 44],on/off ratio [40], retention [45], and on/off ratio, retention and endurance [43] of ECM devices. Our devices also show an increase in on/off ratio with increasing reactivity of $M$, and therefore increased interface layer thickness, of the active metal. 
a

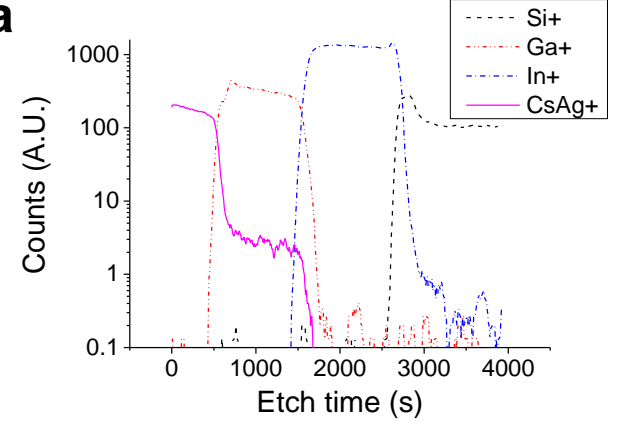

C

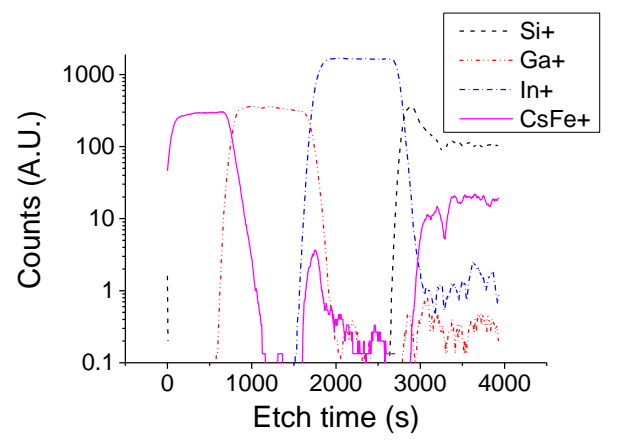

b

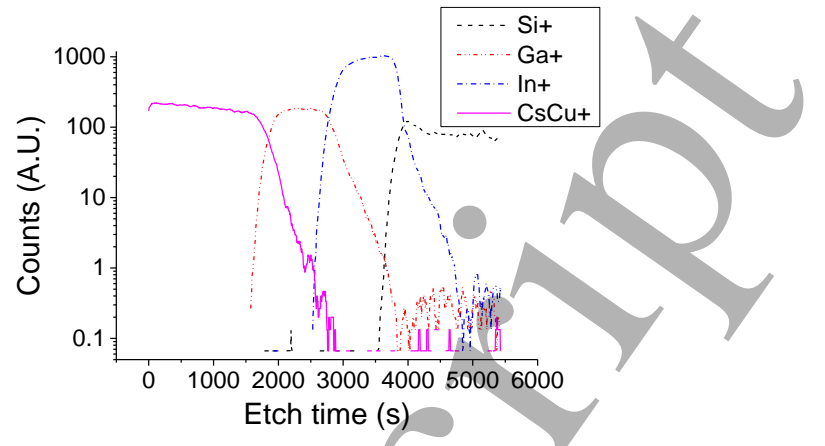

d

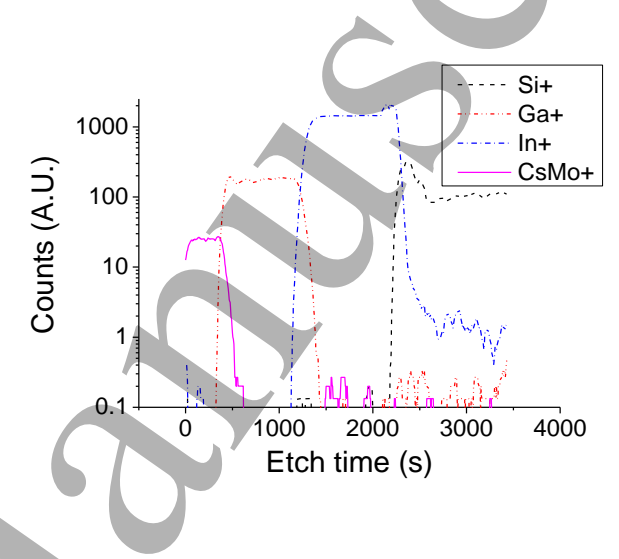

Figure. 3 ToF-SIMS depth profiles showing the strongest signal from each layer in the devices where the active metal and deposition technique is (a) Ag (sputtered), (b) Cu (evaporated), (c) Fe (sputtered), (d) Mo (sputtered).

Figure 3 (a-d) shows the ToF-SIMS depth profiles of $\mathrm{Ag}, \mathrm{Cu}, \mathrm{Fe}$ and Mo devices, respectively. The four layers of the devices can be clearly identified in each case with $\mathrm{M}, \mathrm{GaLaSO}$, ITO and $\mathrm{SiO}_{2}$ represented with $\mathrm{CsM}^{+}, \mathrm{Ga}^{+}, \mathrm{In}^{+}$and $\mathrm{Si}^{+}$, respectively. The strongest signal from $\mathrm{M}$ was from its $\mathrm{Cs}$ compound, as often occurs in SIMS measurements of transition metals [47]. Examination of the penetration of $M$ into the GaLaSO layer, and comparison to Figure 1 and Table 2, shows a greater penetration depth of $\mathrm{M}$ results in lower on and off-state resistivity and better resistive switching ability. Figure 3 (a) shows that the Ag has a uniform concentration in the GaLaSO layer, indicating that it has alloyed with the GaLaSO layer. Figure 3 (b) shows that the $\mathrm{Cu}$ concentration decreases steadily through the GaLaSO layer and reaches the interface with the ITO. Both Ag and Cu devices had repeatable resistive switching. It is also apparent that unlike the other devices were $M$ was sputtered, the In and Ga have penetrated into the layers below them in the $\mathrm{Cu}$ device. This could be due to greater heating of the device during Cu evaporation. Figure 3 (c) shows that the Fe concentration decreases steadily through the GaLaSO layer, but at a greater rate than $\mathrm{Cu}$. There is also some Fe at the GaLaSO/ITO/interface, the Fe could have diffused there itself, or by sputter induced diffusion during the ToF-SIMS measurement. Either situation indicates higher diffusability of $\mathrm{Fe}$ than if there was no Fe at the interface. The Fe devices had short lived and incomplete resistive switching ability. Figure 3 (d) shows that there is very little diffusion of Mo into the GaLaSO layer, and possibly no penetration at all; the Mo devices showed no resistive switching ability. 


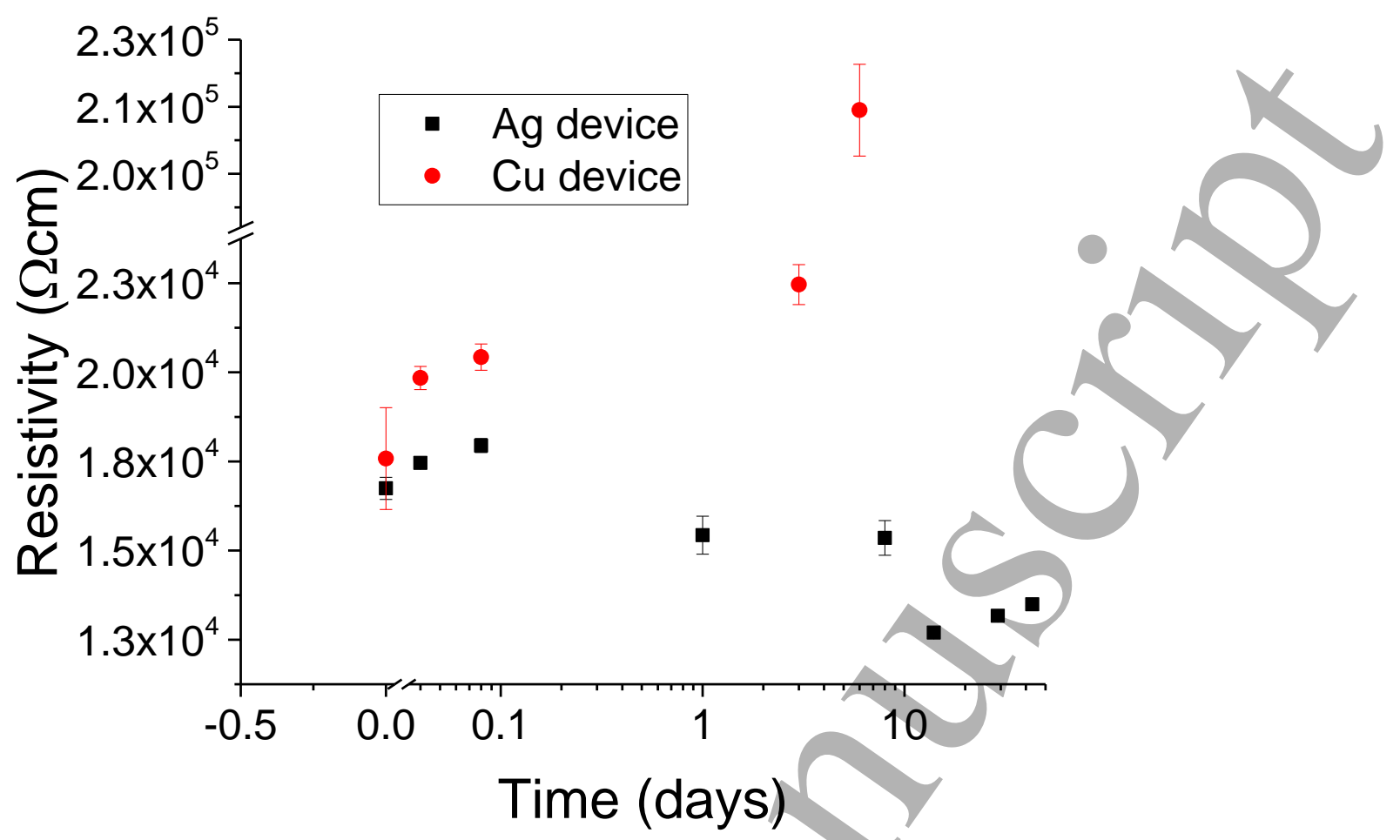

Figure. 4 Retention of the on-state of the $\mathrm{Ag}$ and $\mathrm{Cu}$ devices

To measure the retention of the $\mathrm{Cu}$ and $\mathrm{Ag}$ devices, we swept them from -5 to $5 \mathrm{~V}$ to switch them to a low resistance on-state. We then periodically swept from 0 to $-1 \mathrm{~V}$ and measured the resistance. These results are shown in Figure 4, which shows that the resistivity of the Cu device increases only slightly over three days, but after six days it has increased tenfold, but still an order of magnitude lower than the off-state resistivity. However, the Ag device actually decreases in resistivity by $\sim 15 \%$ up to the end of our measurement at 43 days. The on-state resistivity is largely dictated by the diameter of the filaments [48], which suggests the Ag filament diameter increasing by $\sim 8 \%$. This may be due to the expected high concentration of $\mathrm{Ag}^{+}$ions in the GaLaSO film. $\mathrm{Ag}$ and Cu devices displayed resistive switching for one year after fabrication. However, after two years the devices no longer displayed resistive switching, putting a two year upper limit on the retention. Fresh contacts deposited on two year old GaLaSO film also did not display resistive switching, indicating degradation of the film from exposure to air and/or moisture and that a protective layer over the devices may be necessary. 
a

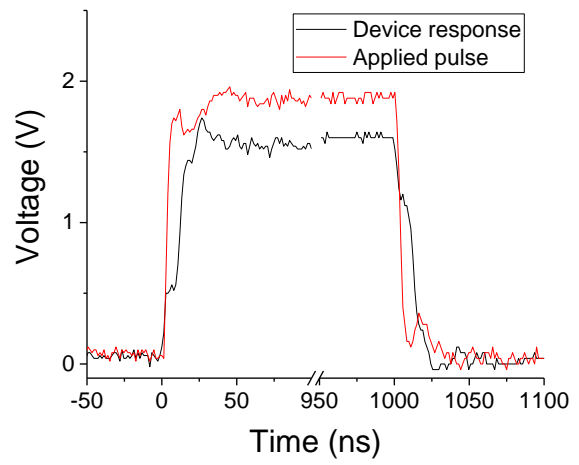

C

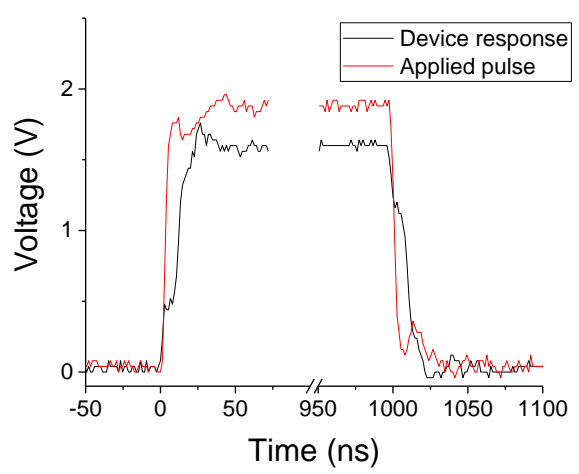

b

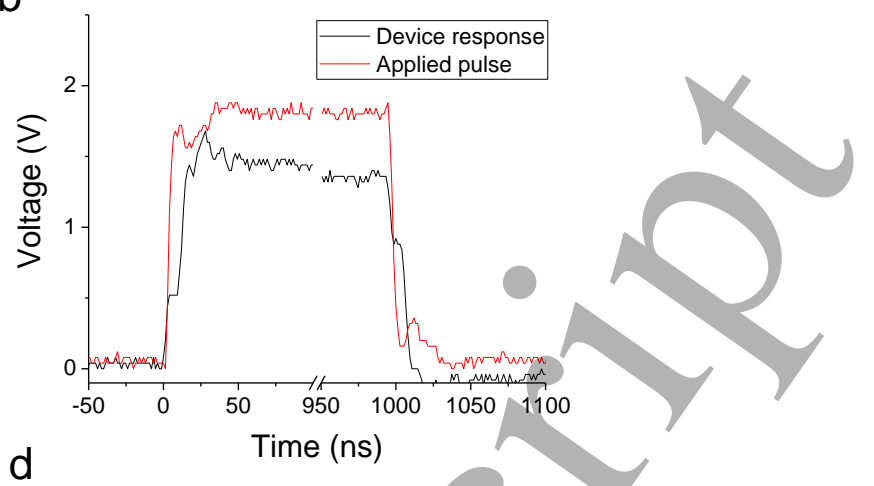

e

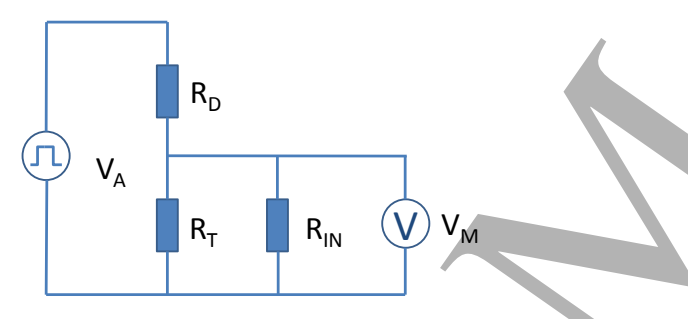

Figure 5 Device response to $1 \mu \mathrm{s}$ pulses applied to a $\mathrm{Cu}(\mathrm{a}), \mathrm{Ag}(\mathrm{b})$ device in a high resistance state, and a $\mathrm{Cu}(\mathrm{c}), \mathrm{Ag}(\mathrm{d})$ device in a low resistance state. (e) Circuit used for the measurement, where $R_{D}$ is the device resistance $=\sim 70 \Omega$ (low resistance state), $\sim 10 \mathrm{k} \Omega$ (high resistance state), $R_{T}$ is the test resistance $=500 \Omega, R_{\mathrm{IN}}$ is the oscilloscope input impedance = $1 \mathrm{M} \Omega, \mathrm{V}_{\mathrm{A}}$ and $\mathrm{V}_{\mathrm{M}}$ are the applied and measured resistances, respectively.

In order to measure the switching speed, we applied $1 \mu$ s pulses of $2 \mathrm{~V}$ to the $\mathrm{Cu}$ and $\mathrm{Ag}$ devices in an off-state that were in series with a $500 \Omega$ test resistor, and monitored the voltage over the test resistor with an oscilloscope, this arrangement is illustrated in Figure 5 (e). Figure 5 (a) and (b) show the device response of the $\mathrm{Cu}$ and $\mathrm{Ag}$ devices, respectively. The $\sim 1.8 \mathrm{~V}$ over $\mathrm{R}_{\mathrm{T}}$ shows that the devices have switched to an on-state. It can be seen that there is a delay of around $15 \mathrm{~ns}$ between the applied pulse and the device response, which is also present at the end of the pulse. In order to check the system response we performed the same measurement for $\mathrm{Cu}$ and $\mathrm{Ag}$ devices in an on-state, Figure 5 (b) and (c), respectively. An almost identical delay can be observed, indicating that the observed delay is due to parasitic capacitance in the measurement system and that the switching speed of the devices is faster than the $10 \mathrm{~ns}$ rise time of the oscilloscope.

We also applied pulses of $2 \mathrm{~V}$ directly to the devices in an off-state, as illustrated in Figure 6 (c), then swept from 0 to $-1 \mathrm{~V}$ to measure the resistance. The devices switched to an on-state with 5 ns pulses, which was the minimum that the pulse generator could deliver. The pulses delivered to the $\mathrm{Cu}$ and $\mathrm{Ag}$ device are illustrated in Figure 6 (a) and (b), respectively. This shows that the switching speed of the $\mathrm{Cu}$ and $\mathrm{Ag}$ devices must be $<5 \mathrm{~ns}$. After switching to an on-state with a $5 \mathrm{~ns}$ pulse both $\mathrm{Cu}$ and $\mathrm{Ag}$ devices could be reset with a reverse sweep of 0 to $-5 \mathrm{~V}$. The switching speeds 
of ECM memory cells with Ag active electrodes and solid electrolytes consisting of GeSe [12] $\mathrm{GeS}_{2}$ [49] were both found to be $50 \mathrm{~ns}$ with an applied voltage $\left(\mathrm{V}_{\text {app }}\right)$ of $1.5 \mathrm{~V}$.

a

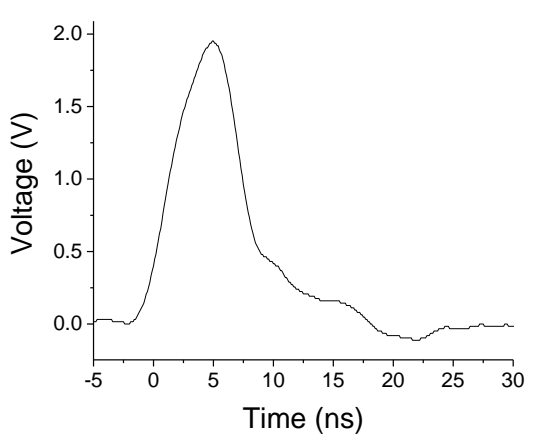

C

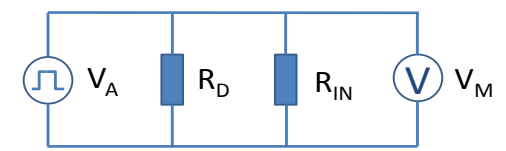

b

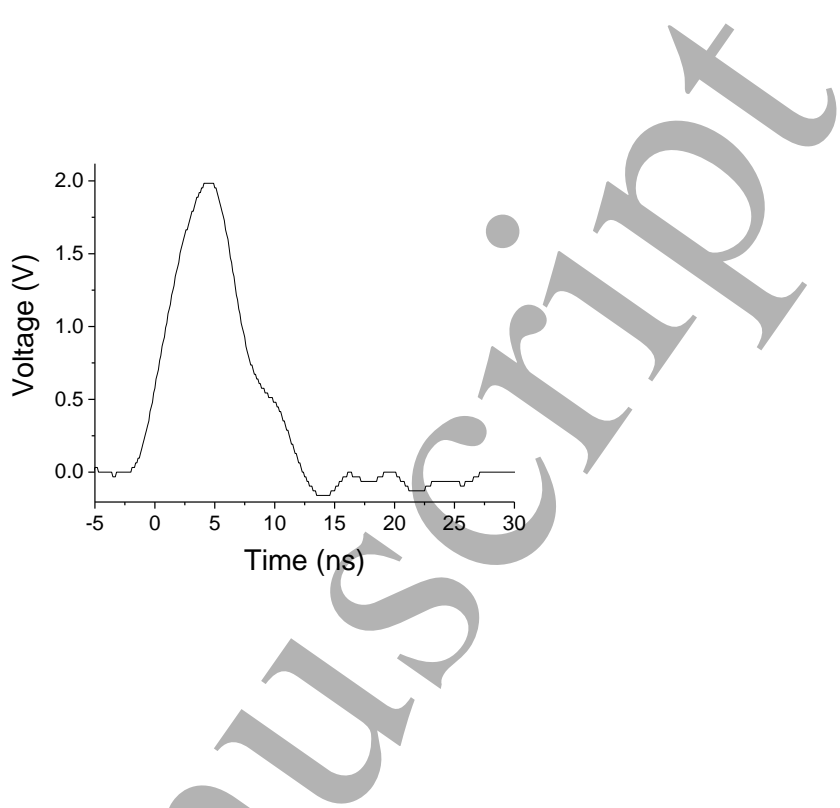

Figure 6 Pule with a 5 ns duration, measured with an oscilloscope with a 10 ns rise time, applied to a Cu device (a) and an Ag device (b) in a high resistance state. (c) circuit used for the pulse measurement.

In Ag-Ge-S ECM cells, switching speed decreases exponentially with $V_{\text {app }}$ [48]. This is expected from the accepted model of the kinetics of filament formation, which is governed by three principle rate limiting processes: (i) nucleation of $\mathrm{M}$ on the inactive electrode, (ii) electron transfer at the metal/solid electrolyte interfaces and (iii) ionic transport through the solid electrolyte [50]. In the nucleation limited regime, there is a rapid exponential decay of the nucleation time with low $V_{\text {app }}$. This exponential decay originates from the exponential dependence of the ion current, $\mathrm{i}_{\mathrm{i}}$, on $V_{a p p}$, and that the filament growth velocity, $v_{f}$, is proportional to $i_{i} / A_{f}$, where $A_{f}$ is the filament cross sectional area [51]. At higher $V_{\text {app }}$, the switching speed is limited by ion mobility, which is $\sim 10^{-2} \mathrm{~cm}^{2} \mathrm{~V}$ ${ }^{1} \mathrm{~s}^{-1}$ for chalcogenides and $\sim 10^{-6} \mathrm{~cm}^{2} \mathrm{~V}^{-1} \mathrm{~s}^{-1}$ for oxides [51], which explains why the switching speed of chalcogenide ECM devices is usually faster than that of oxide ECM devices. The $100 \mathrm{~nm}$ thickness of our GaLaSO film gives room to increase switching speed by decreasing the film thickness, and if our ECM cells are still in the nucleation limited regime, there is the potential for a significant increase in switching speed by increasing $V_{\text {app. }}$.

\section{Conclusions}

In summary, we fabricated ECM cells with an ITO inactive electrode, a GaLaSO solid-electrolyte and sputtered $\mathrm{Ag}, \mathrm{Fe}, \mathrm{Cr}$, and $\mathrm{Mo}$ active electrodes, and evaporated $\mathrm{Cu}$ and $\mathrm{Al}$ active electrodes. $\mathrm{Ag}$ and $\mathrm{Cu}$ devices showed consistent, repeatable resistive switching behaviour with set voltages of $1.4 \mathrm{~V}$ and $0.6 \mathrm{~V}$, respectively. $\mathrm{Cr}$ and Fe devices displayed incomplete or intermittent resistive switching behaviour. Mo and Al devices had no resistive switching. In previous work we found that sputtered $\mathrm{Al}$ active electrodes resulted in repeatable resistive switching behaviour with set voltages of $2.4 \mathrm{~V}$, which we attributed to greater penetration of Al into the surface of GaLaSO when it is sputtered. There was a good correlation between the resistive switching ability of the cell and the penetration depth of M into the GaLaSO layer, as indicated by ToF-SIMS depth profiles. We found that the off- 
state resistivity of the ECM cells tended to increase as the reactivity of $M$ increased, which could be explained by the formation of thicker $\mathrm{MO}_{\mathrm{x}}$ or $\mathrm{MS}_{\mathrm{x}}$ interface layers for $\mathrm{M}$ with higher reactivity. The $\mathrm{Cu}$ and $\mathrm{Ag}$ devices had a retention of 3 and $>43$ days, respectively. We determined the switching speed with two methods, firstly by measuring the device response with an oscilloscope, which indicated a switching speed of $<10 \mathrm{~ns}$ for both $\mathrm{Cu}$ and $\mathrm{Ag}$ devices, and by observing switching after delivering a $5 \mathrm{~ns}$ pulse, which indicated a switching speed of $<5 \mathrm{~ns}$ for both $\mathrm{Cu}$ and $\mathrm{Ag}$ devices. The switching speed of $<5 n$ is the fastest reported for a chalcogenide ECM cell by an order of magnitude.

\section{Acknowledgments}

Chalcogenide glass was provided through EPSRC grant EP/M015130/1, Manufacturing and Application of Next Generation Chalcogenides.

[1] Eggleton B J, Luther-Davies B and Richardson K 2011 Chalcogenide photonics Nat Photon 5 141-8

[2] Hughes M A, Fedorenko Y, Gholipour B, Yao J, Lee T-H, Russell M G, Homewood K P, Hinder S, Hewak D W, Elliott S R and Curry R J 2014 N-type chalcogenides by ion implantation Nat. Commun. 55346

[3] Kolobov A V and Elliott S R 1991 Photodoping of amorphous chalcogenides by metals Adv. Phys. 40 625-84

[4] Dong W, Krbal M, Kalikka J, Chin X Y, Gholipour B, Soci C, Fon's P J, Mitrofanov K V, Chen L and Simpson R E 2016 Enhanced Sb2S3 crystallisation by electric field induced silver doping Thin Solid Films 616 80-5

[5] Patil D S, Konale M S, Kolar J, Shimakawa K, Zima V and Wagner T 2015 Ionic conductivity study of Lil-Ga2S3-GeS2 chalcogenide glasses using a random-walk approach Pure Appl. Chem. 87 249-59

[6] Loke D, Lee T H, Wang W J, Shi L P, Zhao R, Yeo Y C, Chong T C and Elliott S R 2012 Breaking the Speed Limits of Phase-Change Memory Science 336 1566-9

[7] Yang Y C, Pan F, Liu Q, Liu M and Zeng F 2009 Fully Room-Temperature-Fabricated Nonvolatile Resistive Memory for Ultrafast and High-Density Memory Application Nano Lett. 9 1636-43

[8] Lee M J, Park Y, Suh D S, Lee E H, Seo S, Kim D C, Jung R, Kang B S, Ahn S E, Lee C B, Seo D H, Cha Y K, Yoo I K, Kim J S and Park B H 2007 Two Series Oxide Resistors Applicable to High Speed and High Density Nonvolatile Memory Adv. Mater. 19 3919-23

[9] Mehonic A, Cueff S, Wojdak M, Hudziak S, Jambois O, Labbé C, Garrido B, Rizk R and Kenyon A J 2012 Resistive switching in silicon suboxide films J. Appl. Phys. 111074507

[10] Yang J J, Strukov D B and Stewart D R 2013 Memristive devices for computing Nat. Nanotechnol. 813

[11] Li Y, Zhong Y P, Xu L, Zhang J J, Xu X H, Sun H J and Miao X S 2013 Ultrafast Synaptic Events in a Chalcogenide Memristor Sci. Rep. 31619

[12] Dietrich S, Angerbauer M, Ivanov M, Gogl D, Hoenigschmid H, Kund M, Liaw C, Markert M, Symanczyk R, Altimime L, Bournat S and Mueller G 2007 A nonvolatile 2-Mbit CBRAM memory core featuring advanced read and program control IEEE J. Solid-State Circuit 42 83945

[13] Govoreanu B, Kar G, Chen Y, Paraschiv V, Kubicek S, Fantini A, Radu I, Goux L, Clima S and Degraeve R 2011 10× 10nm $2 \mathrm{Hf} / \mathrm{HfO}$ x crossbar resistive RAM with excellent performance, reliability and low-energy operation. In: Electron Devices Meeting (IEDM), 2011 IEEE International: IEEE) pp 31.6. 1-.6. 4 
[14] Kim S, Park J, Jung S, Lee W, Woo J, Cho C, Siddik M, Shin J, Park S, Lee B H and Hwang H 2011 Excellent resistive switching in nitrogen-doped $\mathrm{Ge}_{2} \mathrm{Sb}_{2} \mathrm{Te}_{5}$ devices for fieldprogrammable gate array configurations Appl. Phys. Lett. 99192110

[15] Pradel A, Frolet N, Ramonda M, Piarristeguy A and Ribes M 2011 Bipolar resistance switching in chalcogenide materials Phys. Status Solidi A-Appl. Mat. 208 2303-8

[16] Hirose $\mathrm{Y}$ and Hirose $\mathrm{H} 1976$ Polarity-dependent memory switching and behavior of $\mathrm{Ag}$ dendrite in Ag-photodoped amorphous $\mathrm{As}_{2} \mathrm{~S}_{3}$ films J. Appl. Phys. 47 2767-72

[17] Reso D, Silinskas M, Lisker M, Schubert A and Burte E P 2011 Hot wire chemical vapor deposition of germanium selenide thin films for nonvolatile random access memory applications Appl. Phys. Lett. 98151901

[18] Soni R, Meuffels P, Petraru A, Weides M, Kugeler C, Waser R and Kohlstedt $H 2010$ Probing $\mathrm{Cu}$ doped $\mathrm{Ge} 0.3 \mathrm{Se} 0.7$ based resistance switching memory devices with random telegraph noise J. Appl. Phys. 107024517

[19] Choi S-J, Park G-S, Kim K-H, Cho S, Yang W-Y, Li X-S, Moon J-H, Lee K-J and Kim K 2011 In Situ Observation of Voltage-Induced Multilevel Resistive Switching in Solid Electrolyte Memory Adv. Mater. 23 3272-7

[20] Waser R, Dittmann R, Staikov G and Szot K 2009 Redox-Based Resistive Switching Memories - Nanoionic Mechanisms, Prospects, and Challenges Adv. Mater. 21 2632-63

[21] Wang F, Dunn W P, Jain M, De Leo C and Vickers N 2011 The effects of active layer thickness on Programmable Metallization Cell based on Ag-Ge-S Solid-State Electron. 61 33-7

[22] Velea A, Opsomer K, Devulder W, Dumortier J, Fan J, Detavernier C, Jurczak M and Govoreanu B 2017 Te-based chalcogenide materials for selector applications Sci. Rep. 78103

[23] Lu D and Wong C P 2016 Materials for Advanced Packaging pg. 270: Springer International Publishing)

[24] Seshan K and Schepis D 2018 Handbook of Thin Film Deposition pg. 242: Elsevier Science)

[25] Yoshimasu T, Akagi M, Tanba N and Hara S 1998 An HBT MMIC power amplifier with an integrated diode linearizer for low-voltage portable phone applications IEEE J. Solid-State Circuit 33 1290-6

[26] Hewak D W, Brady D, Curry R J, Elliott G, C.Huang C, Hughes M, Knight K, Mairaj A, Petrovich M N, Simpson R and Sproat C 2010 Photonic glasses and glass-ceramics ed G S Murugan

[27] Morales-Sanchez E, Prokhorov E, Mendoza-Galván A and González-Hernández J 2002 Determination of the glass transition and nucleation temperatures in $\mathrm{Ge}_{2} \mathrm{Sb}_{2} \mathrm{Te}_{5}$ sputtered films J. Appl. Phys. 91 697-702

[28] Sarrach D J, De Neufville J P and Haworth W L 1976 Studies of amorphous Ge-Se-Te alloys (I): Preparation and calorimetric observations J. Non-Cryst. Solids 22 245-67

[29] Skripachev I V, El - Amraoui M, Messaddeq Y and Santagneli S H 2013 Study of the Glass Transition Temperature of As - S Glasses for the Fabrication of Chalcogenide Optical Fibers International Journal of Applied Glass Science 4 256-65

[30] Curry R J, Mairaj A K, Huang C C, Eason R W, Grivas C, Hewak D W and Badding J V 2005 Chalcogenide Glass Thin Films and Planar Waveguides J. Am. Ceram. Soc. 88 2451-5

[31] Brady D J 1999 Gallium lanthanum sulphide based glasses for mid-infrared optical fibres. In: Optoelectronics Research Centre: University of Southampton)

[32] Frantz J A, Shaw L B, Sanghera J S and Aggarwal I D 2006 Waveguide amplifiers in sputtered films of Er3+-doped gallium lanthanum sulfide glass Opt. Express 14 1797-803

[33] Hughes M A, Fedorenko Y, Gwilliam R M, Homewood K P, Hinder S, Gholipour B, Hewak D W, Lee T-H, Elliott S R and Curry R J 2014 Ion-implantation-enhanced chalcogenide-glass resistive-switching devices Appl. Phys. Lett. 105083506

[34] Prakash S and Yeom J 2014 Nanofluidics and Microfluidics: Systems and Applications vol p. 107: Elsevier Science)

[35] Goux L and Valov I 2016 Electrochemical processes and device improvement in conductive bridge RAM cells physica status solidi (a) 213 274-88 
[36] Tappertzhofen S, Valov I, Tsuruoka T, Hasegawa T, Waser R and Aono M 2013 Generic relevance of counter charges for cation-based nanoscale resistive switching memories ACS nano 7 6396-402

[37] Yang Y, Gao P, Li L, Pan X, Tappertzhofen S, Choi S, Waser R, Valov I and Lu W D 2014 Electrochemical dynamics of nanoscale metallic inclusions in dielectrics Nat. Commun. 5 4232

[38] Lübben M, Menzel S, Park S, Yang M, Waser R and Valov I 2017 SET kinetics of electrochemical metallization cells: influence of counter-electrodes in $\mathrm{SiO}_{2} / \mathrm{Ag}$ based systems Nanotechnology 28135205

[39] Hou Y, Wang D, Yang X H, Fang W Q, Zhang B, Wang H F, Lu G Z, Hu P, Zhao H J and Yang H G 2013 Rational screening low-cost counter electrodes for dye-sensitized solar cells Nat. Commun. 41583

[40] Hasan M, Dong R, Choi H, Lee D, Seong D-J, Pyun M and Hwang H 2008 Uniform resistive switching with a thin reactive metal interface layer in metal-La $0.7 \mathrm{Ca} 0.3 \mathrm{Mn} \mathrm{O} 3$-metal heterostructures Appl. Phys. Lett. 92202102

[41] Shen W, Dittmann R, Breuer U and Waser R 2008 Improved endurance behavior of resistive switching in (Ba, Sr) TiO 3 thin films with W top electrode Appl. Phys. Lett. 93222102

[42] Lin C-Y, Wu C-Y, Wu C-Y, Tseng T-Y and Hu C 2007 Modified resistive switching behavior of $\mathrm{ZrO}_{2}$ memory films based on the interface layer formed by using Ti top electrode J. Appl. Phys. 102094101

[43] Lee C-J, Chang Y-C, Wang L-W and Wang Y-H 2017 Nonvolatile Resistive Switching Memory Utilizing Cobalt Embedded in Gelatin Materials 1132

[44] Lv H, Wang M, Wan H, Song Y, Luo W, Zhou P, Tang T, Lin Y, Huang R and Song S 2009 Endurance enhancement of Cu-oxide based resistive switching memory with Al top electrode Appl. Phys. Lett. 94213502

[45] Cho D-Y, Luebben M, Wiefels S, Lee K-S and Valov I 2017 Interfacial Metal-Oxide Interactions in Resistive Switching Memories ACS Applied Materials \& Interfaces 9 19287-95

[46] Jeong H Y, Kim S K, Lee J Y and Choi S-Y 2011 Role of interface reaction on resistive switching of metal/amorphous TiO2/AI RRAM devices Journal of The Electrochemical Society 158 H979-H82

[47] Gerardi C and Massaro C 1995 On the Improvement of SIMS Technique by the Use of MCs Molecular lons Microsc. Microanal. 6 523-31

[48] Russo U, Kamalanathan D, lelmini D, Lacaita A L and Kozicki M N 2009 Study of multilevel programming in programmable metallization cell (PMC) memory IEEE Trans. Electron Devices 56 1040-7

[49] Gopalan C, Ma Y, Gallo T, Wang J, Runnion E, Saenz J, Koushan F, Blanchard P and Hollmer S 2011 Demonstration of Conductive Bridging Random Access Memory (CBRAM) in logic CMOS process Solid-State Electron. 58 54-61

[50] Menzel S, Tappertzhofen S, Waser R and Valov I 2013 Switching kinetics of electrochemical metallization memory cells PCCP Phys. Chem. Chem. Phys. 15 6945-52

[51] Kozicki M N, Mitkova M and Valov I 2015 Electrochemical metallization memories, ed D Ielmini: Wiley) 